\title{
news
}

\section{PCD research recipients announced}

The four winners of the Colgate PCD Research Awards in partnership with the Oral Dental Research Trust were announced at the recent British Dental Exhibition and Conference.

Miss Nicola Ling, Miss Lindsay Allen, Mrs Francesca Barclay and Mr Trevor Coward were each awarded $£ 2,500$. The aim of the awards is to support investigations of clinical relevance, particularly in the field of preventive care.

The awards were presented by Professor Nairn Wilson, Chairman and Acting Director of the ODRT, who described the awards as 'an important forward looking initiative in helping to build and strengthen the academic base of the dental team.

Miss Ling and Mr Coward were present to receive their awards. Miss Ling is Staff/Tutor Hygienist, School of Dental Hygiene \& Therap at Birmingham Dental Hospital. Mr

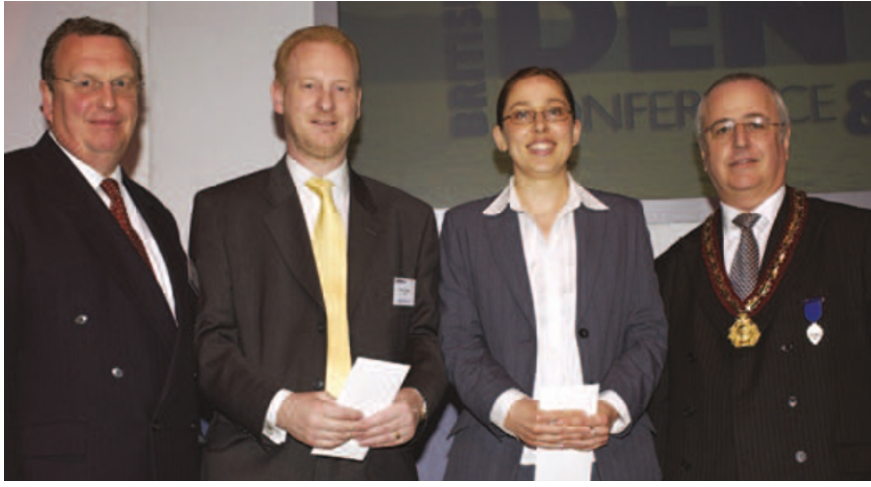

Coward is Lecturer in Craniofacial \& Maxillofacial Technolog at Guy's, King's \& St Thomas' Dental Institute.

Pictured (left to right) Professor Nairn Wilson, Mr Coward, Miss Ling and Tony Kravitz, President of the BDA.

\section{New degree for Dental nurse takes up Mastermind challenge} \section{technicians}

A foundation degree in dental technology being developed at $\mathrm{De}$ Montfort University in Leicester is likely to become a registrable qualification for dental technicians.

The General Dental Council has received a paper from the Dental Technicians' Association on the proposed foundation degree, which would lead to an Hons BSC programme in Dental Technology.

The 12 foundation degree modules have been developed to cover the GDC curriculum for registered dental technicians. The programme is being validated by De Montfort University and will be delivered in Further Education colleges across the UK. The validation involves GDC visitors and a GDC visit team will visit the programme when it is up and running.

BSc degrees in dental technology are already available at Cardiff and Manchester.

Are you eligible for entry onto the $\mathrm{PCD}$ register via the transitional entry route? Turn to page 18 to find out.

06 summer 04

vital
Dental nurse advisor Linda Bussey stepped up to the infamous 'Mastermind' chair recently in an effort to encourage young people into dental nursing.

Linda, who works as a dental nurse advisor for Bradford South \& West PCT and Bradford City Teaching PCT, took part in NHS Mastermind, an annual event in which students across the Bradford district get the chance to put local health service staff under the spotlight.

'When I volunteered for NHS Mastermind it occurred to me that very few people know what a dental nurse actually does,' says Linda. 'this was my chance to tell the future workforce about dental nursing as a career choice.'

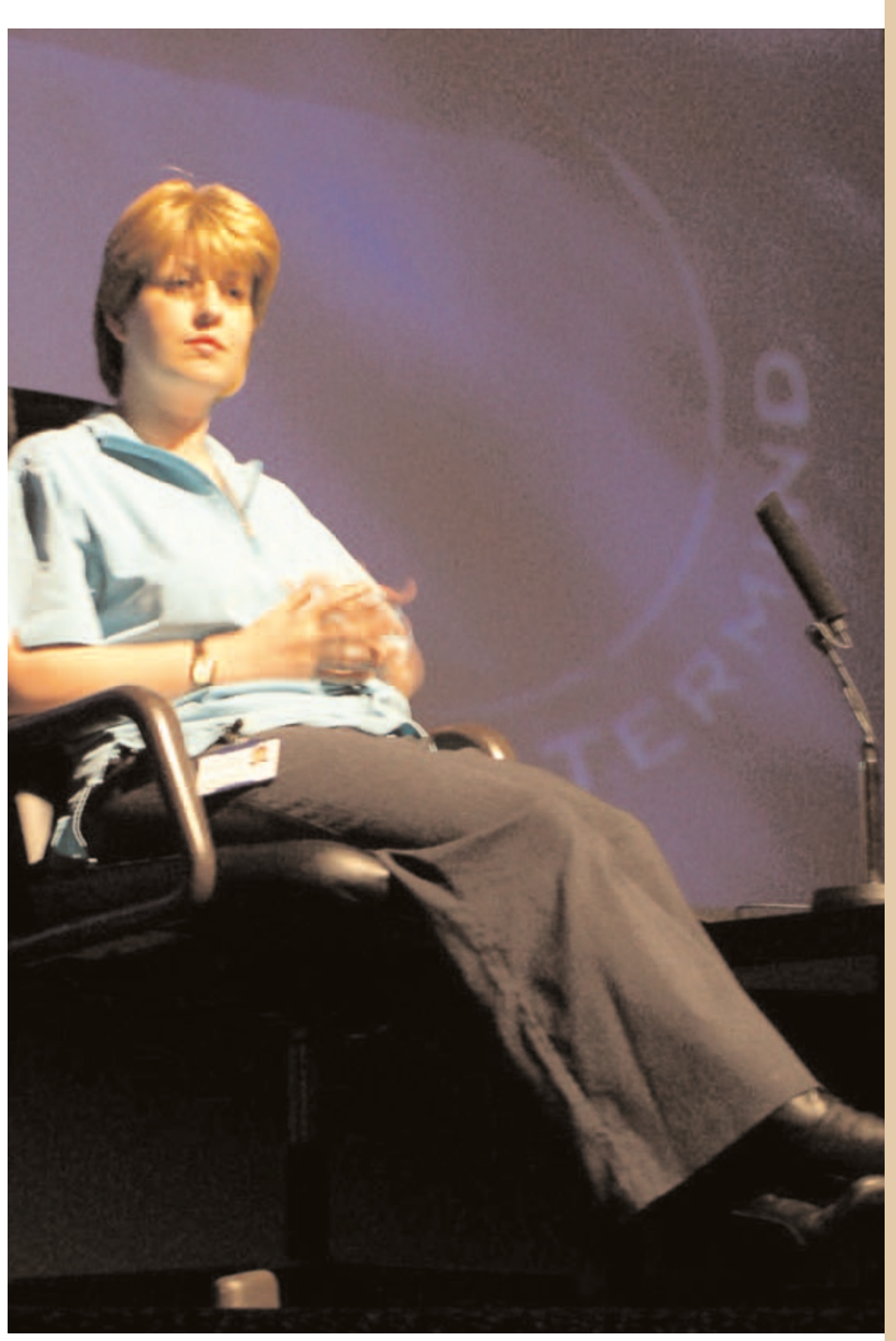




\section{news in brief}

In development

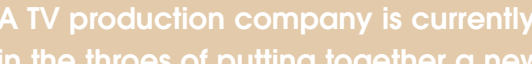

docusoap that centres around a bus

UK dental surgery. The Dentist is to be

a TV programme similar to Vets in

Practice. After requests for dentists

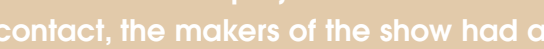

great response and have now whitte
down the choice to three surgeries.

the next stage is for one of the

practices to be chosen to star in the

show. Waich this soace?

\section{Decade for ONG}

This month sees the 10th anniversary

of the formation of the Orthodontic

National Group. During the past 10

years the group has initiated the

Certificate in Orthodontic Nursing, the

new PCD class of orthodontic

therapists and has contributed to

continued professional education. The

group has held 14 regional study

days, nine dental nurse days at the

British Orthodontic Conference and

two annual competitions.

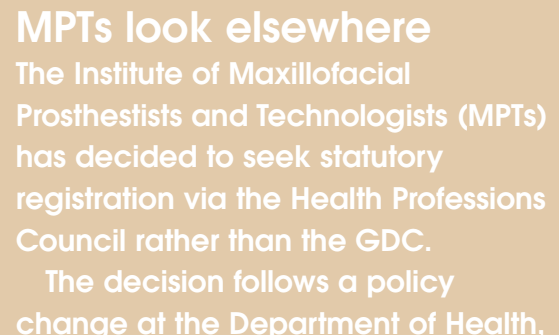

which felt that it would be more

gopropriate for the MPIs to be

registered amongst other groups of
healihcare scientists, as most of the

work undertiken by MPIs is non.

\section{Training top up}

The GDC is considering the possibility of an educational provider developing 'top-up' training for dental nurses who have some experience but not enough to meet the grandparenting requirements when the PCD register opens. This would provide a route by which such dental nurses could become registered.

\section{Team members scoop awards}

There were a whole host of winners from the dental team at this year's Dental Awards 2004, which took place at the Royal Lancaster Hotel in London.

The Crescent Specialist Dental Centre in Devon scooped three awards, Overall Team of the Year, Best Practice Environment and Hygienist of the Year won by Maureen Milne.

Kendrick View Dental Practice in Berkshire was awarded Best Dental Team Support Programme while its Practice Manager Judith Chandler collected the award for Practice Manager of the Year. Sara Calder of The Orthodontic Centre in South Yorkshire was awarded Dental Nurse of the Year and Brendan Hudson of PDS Dental Laboratory in Leeds (pictured) received the award for Dental Technician of the Year. Brenda Rawles from Octagon Orthodontics in Buckinghamshire collected the award for

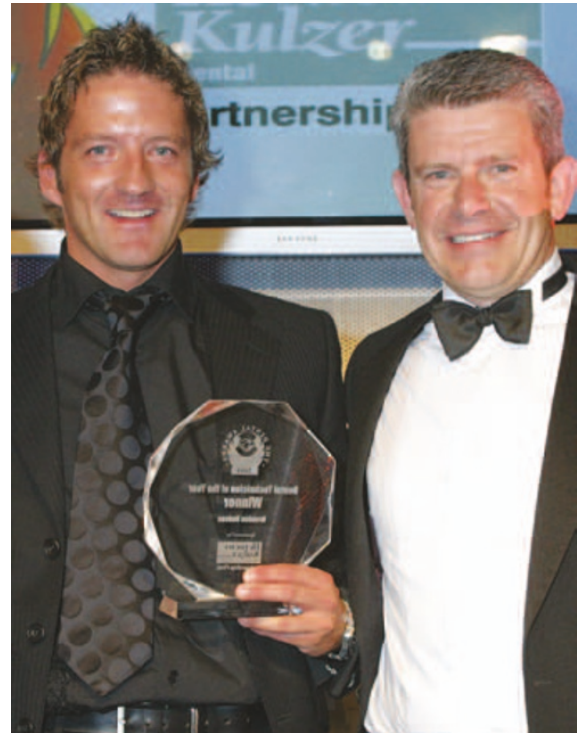

Dental Receptionist of the Year and finally Dental Laboratory of the Year was awarded to Knight Dental Design in London.

The event was organised by Highbury Business Health Care and the British Dental Health Foundation.

\section{GDC get go-ahead from Government \\ The Government has confirmed that

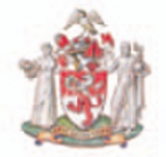
new legislation that will enable the next round of General Dental Council reforms to go ahead should be in place by January 2005.

The legislation will give the GDC new powers to extend statutory GDC registration to cover the whole dental team, including dental nurses and dental technicians, set up a complaints scheme for non-NHS dental patients and reform its procedures for dealing with misconduct and ill health amongst dental professionals. In addition it will introduce new procedures to tackle problems of poor performance in dentists and remove the current restriction on the number of dental bodies corporate.

The GDC's reform programme is being implemented through a series of amendments - Section 60 orders to the Dentists Act. Section 60 orders give the Government the power to change regulations, Orders or Acts of

\section{General Dental Council}

Parliament without the need for a Bill to go through the parliamentary procedure leading up to a new Act of Parliament.

GDC President Hew Mathewson welcomed the confirmation of the new legislation and said that the GDC was pressing ahead with work at their end to ensure the initiatives were set to go live as soon as practicable once the legislation was in place.

Registration fees for all registrants for 2005 have yet to be discussed by the GDC and the Council does not currently know what PCD fees will cost. However, there will be an initial registration fee and then an annual retention fee to stay on the register, which will be one fee per person, not one fee per title as there is now. The GDC intends to publish information on fees as soon as possible. 


\section{New rules for PCDs from Europe}

The GDC has introduced a new registration process for dental hygienists and therapists who come from the European Union, Norway, Iceland or Switzerland.

From 1 May 2004 nationals of these countries have had their applications individually assessed by external assessors. The assessors, who are all dental training experts, compare the applicant's qualifications, training and professional experience with UK standards and then recommend whether or not the person is adequately qualified and skilled to be enrolled with the Council and allowed to work in the UK.

Under European Union rules a person who fails such an assessment can choose to undergo a period of extra supervised training, to make up the lack of experience or knowledge, or can decide to sit an examination.

The General Dental Council decided to introduce the new procedures in order to be able to check the training standards of dental hygienists and therapists from all the EU countries - including the 10 new countries which joined the EU on 1 May - plus Norway, Iceland and Switzerland. It claims that the new individual assessment of applications will help it to check standards and protect the public.

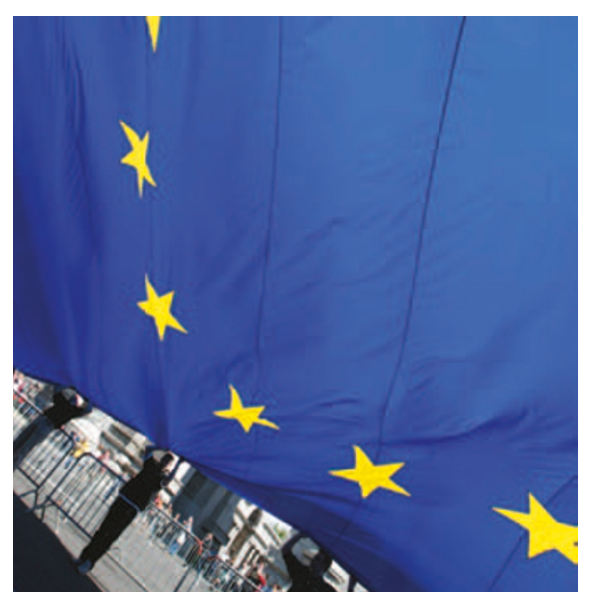

08 summer 04

vital

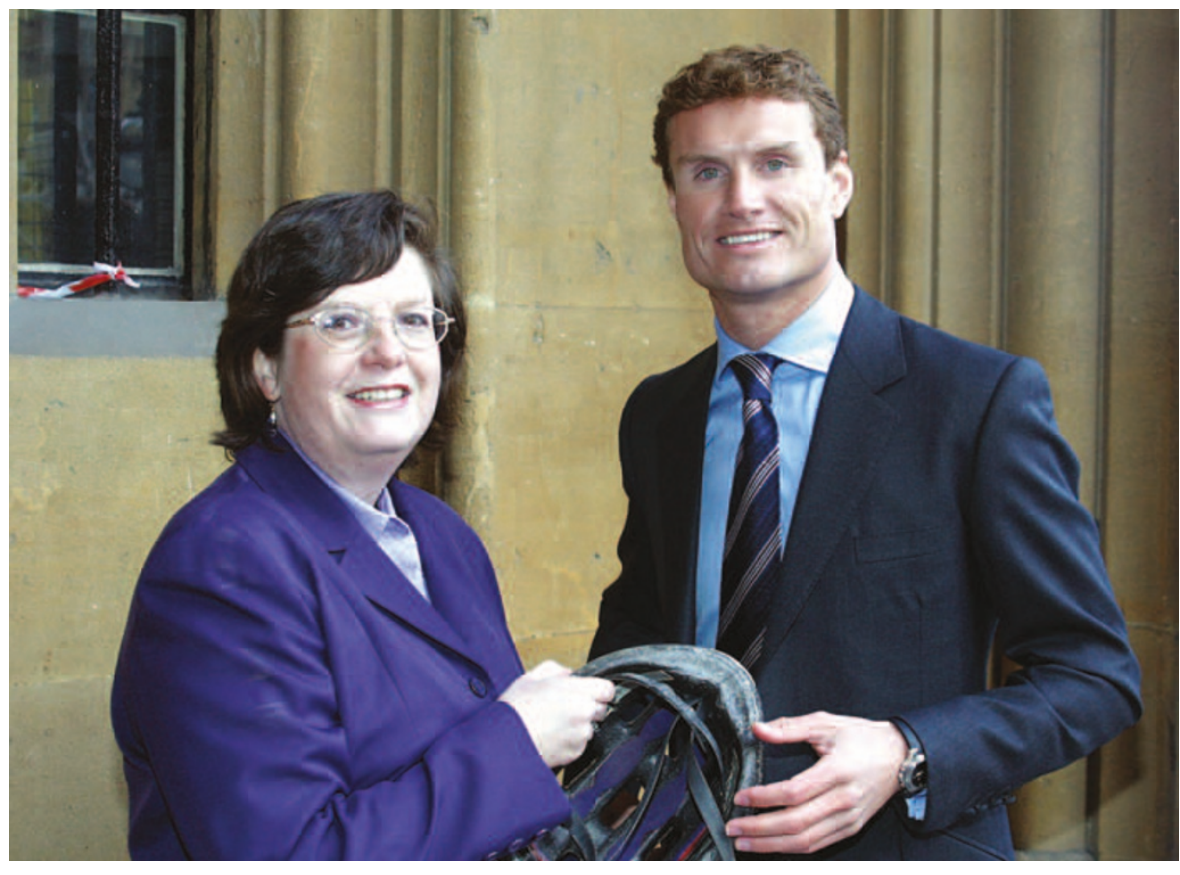

\section{Racing ace supports campaign}

Registered specialist in paediatric dentistry Helen Chapman (above left) has campaigned vigorously to bring about more awareness for the need for head protection to help reduce the impact of injuries to the head/face which can cause serious facial and dental injuries to children. The 'Protective Head Gear for Young Cyclist Bill' had its second reading on 23 April. Formula 1 racing star David Coulthard (above right) lent his support to the campaign at the launch of the Private Members Bill at the Palace of Westminster.

\section{Oral Health Month launched}

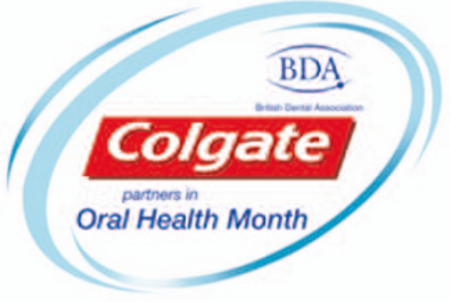

At the recent BDA conference held in Bournemouth, Colgate, in partnership with the BDA, unveiled the 2004 Oral Health Month initiative. Colgate Oral Health Month, now in its third year, has become a leading UK campaign for establishing and promoting better oral health habits.

Last year over 4,300 practices participated. This year's campaign, in partnership with the $\mathrm{BDA}$, will contain key messages to drive awareness of the general public that it's never too late to change habits and improve your oral health.

\begin{tabular}{l} 
Register nOW \\
\hline Colgate Oral Health Month 2004 \\
will take place in September. \\
Dental professionals are crucial to \\
delivering these key messages \\
so; once again, Colgate is \\
looking for active involvement \\
from dental professionals. \\
Practices registering will receive \\
the new Colgate Oral Health \\
Month pack, developed following \\
research carried out with previous \\
participants. This pack will \\
contain educational materials, \\
patient toothpaste samples, \\
posters, competition details and \\
other fun patient items. \\
If you would like to register call \\
Colgate on 01483401901.
\end{tabular}




\section{Oldham nurses benefit from bursary}

Three student dental nurses are the first to benefit from a training bursary launched by health chiefs in memory of a dedicated Oldham dental nurse who died last year.

The Naveed Maqsood Training Bursary was launched after the tragic death of the 23-yearold from cancer in June last year.

Naveed had spent two years on the PCT's bilingual dental nurse training programme before joining John Scott's dental practice in Leeds.

Now student dental nurses Bushra Ibrar, 31, Rohima Khatun, 21 and 20-year-old Joohora Begum will all have the chance to take part in extra training to improve their skills - and help their patients.

'The dentists need nurses who have a range of skills' says Rohima. 'Thanks to the bursary, I'll be able to assist the dentist with sedation and because I'm bilingual I can also explain to Bengali patients what we are doing and why'

\section{CoDTEI}

The newly formed Conference of Dental Technology Educational Institutes (CoDTEI) held its first meeting recently in London. The group comprises dental technology teaching staff, managers and directors who are also registered dental technicians in participating educational institutes in the UK.

During the conference a range of topics were aired from consideration of the wider EU perspective to the business meeting rules. Antony Townsend, Registrar of the GDC, provided delegates with an up to date overview of the progress towards the statutory registration.

The Chief Dental Officer for England, Professor Raman Bedi, also formally congratulated them for taking the conference

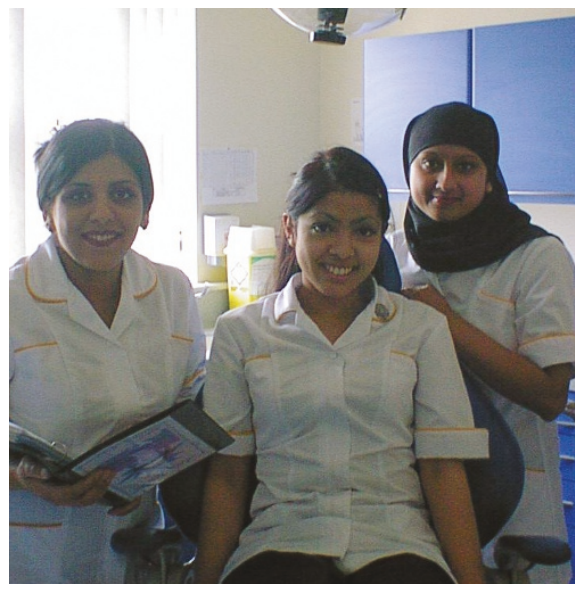

From left: Bushra Ibrar, Rohima Khatun in the dentist's chair, and Joohora Begum

The bursary is open to any bilingual PCT employee, not just dentistry staff and will provide $£ 1,000$ annually, which can be used to pay for anything from training courses to books.

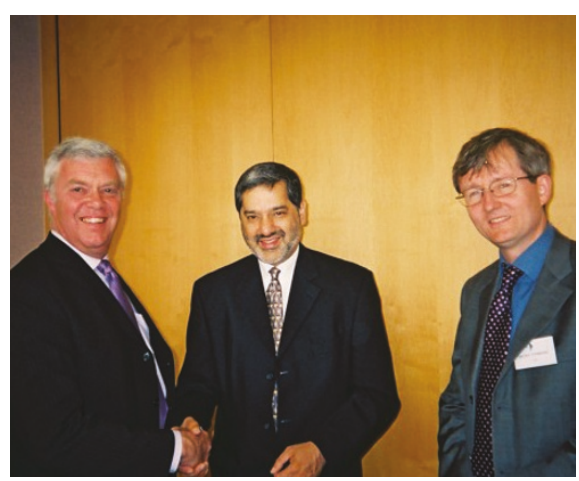

forward to develop closer liaison and improving the provision of dental technology training for the registrable qualifications within the UK.

Pictured from left to right: Tony Griffin, Manager of the School of Dental Nursing and Dental Technology, Chief Dental Officer, Raman Bedi and Antony Townsend, Registrar of the GDC.

\section{Orthodontic nurse award}

The Orthodontic National Group is inviting entries for the Orthodontic Dental Nurse Award 2004, which is now in its ninth year. Nurses can enter by sending a short synopsis on a subject relevant to orthodontics to the judges, and out of these entries five finalists will be selected. They are then to give a 10 minute presentation at the British Orthodontic Conference in September before the winner is chosen. The winner will also be invited to present at a similar competition at the 6th International Orthodontic Congress in Paris in 2005. The award was set up to encourage and develop the knowledge and skills in this area, and winners receive a prize of $£ 300$ as well as the award. 